\title{
The Effect of Pre-Testing in a Private Pilot Fundamentals Class
}

\author{
Wendy S. Beckman \\ Middle Tennessee State University
}

\begin{abstract}
The positive effect of pre-testing in an Introduction to Aerospace class at Middle Tennessee State University (MTSU) has been previously documented and published. The purpose of this study was to apply the same study methodology to a different group of students, those who were enrolled in the Private Pilot Fundamentals class at MTSU in the spring of 2007. One section of the course was given a pre-test at the beginning of each unit of study, while another section was given a list of learning objectives for each unit. The subsequent unit post-test performance of each class was analyzed. Based on the results, pre-testing was found to be a useful learning aid for students in terms of subsequent post-test performance. However, it was not as helpful for the Private Pilot Fundamentals students as it was for the Introduction to Aerospace students in the previous study.
\end{abstract}

\section{INTRODUCTION}

During the last ten to fifteen years, K-12 education has embraced and experienced success with the concept of student pre-testing. In that environment, pre-tests are typically used to determine if students have the prerequisite skills needed for the upcoming unit of instruction, or to what extent students have already achieved the objectives of the planned instruction (Linn \& Miller, 2005). While these functions are equally applicable in higher education, there are other benefits as well. In the collegiate environment, the pre-testing methodology has not been widely utilized, but from the literature available, the additional value of pre-testing for college students seems to lie in clearly laying out the expectations of what students are to learn and demonstrating the amount of learning that is taking place (Vocational Instructional Materials Lab, 1998).

A review of the literature on pre-testing in the collegiate environment reveals a limited number of publications, found in disparate disciplines. What is interesting is that each of these articles reported success in the classroom using pre-testing concepts, even though they were implemented in a variety of ways. Shepard (2001, p. 1091) found that assessing prior knowledge and experience not only improved her teaching, but also drew students into the habit of reflecting on their own knowledge. She states:

After all, what safer time to admit what you do not know than at the start of an instructional activity? What better way to demonstrate to students that assessment (knowing what you know and what you do not know) helps learning?

In science education, Liggett-Fox (1997, p. 29) found that pre-testing can assist students in laying aside their previous misconceptions about a topic:

...too often we don't investigate what misconceptions our students have. Even if we find out what beliefs our students have, we assume that giving them the "correct" information will make them abandon their misconceptions and adopt the new information. We need to understand that students form misconceptions based on their experiences. As a result, our students do not have any motivation to give up their closely held beliefs because their misconceptions seem to work...

By having questions scored "incorrect" on a pre-test, she found that her students were more interested in finding out why they missed the question, leading them to consider the possibility that their basic premises were incorrect.

A chemistry professor (Ochs, 1998, p. 401 $\& 403$ ) found that the benefit of pre-testing in his upper level course was to have students realize what they did not know about fundamental chemistry, which in turn made them more receptive to continued chemical education. He reported that: 
Having given such tests for three years now, I can report that the benefits exceeded expectations. Not only do most students now attend to fundamental chemical ideas, but also the entire approach to the course is much more positive.... in previous years, without the pre-test, students were listless, and few took notes in the first day lecture. By contrast, after the quiz, the response to the first lecture was entirely different: the students were deadly silent, all took copious notes and they listened intently. A further benefit was that many overcame their timidity in asking even simple questions. This approach can make students aware of what they don't know and provide an impetus to deepen their understanding of basic concepts.

One theme that ran through the literature was the critical importance of being clear regarding the objectives of the course. The act of preparing pre-tests, whether for an entire course or a particular unit, acted as an impetus for faculty to become very clear in their own minds of the important objectives of the course. An education professor (Bernauer, 1998, p. 26) commented:

The decision to develop a measurementdriven method resulted from my growing awareness that instead of teaching the most important knowledge, skills, and attitudes that my students needed to attain, I had fallen victim to the trap of trying to "cover the material." I decided, therefore, that it was necessary, first, to identify critical learning goals, and then, based on these goals, to develop assessment items to guide my teaching, student learning, and the evaluation of student achievement.

Further findings to this effect were indicated by Stiggins (1994) who found that the most serious impediment to improving education was not the quality of either instruction or assessment, but rather the failure of instructors to identify clearly what were the most important objectives for learning. Angelo and Cross (1993, p. 8) put it simply: "Before faculty can assess how well their students are learning, they must identify and clarify what they are trying to teach." Additionally, given that most students will study primarily what they perceive they will be tested on, it is imperative that faculty ask the right questions in assessment situations (Resnick \& Resnick, 1992). Consequently, it is critical to first identify an achievable set of the most important curricular goals, and then to ensure that objectives, instruction, and assessment items each align with these goals (Bernauer, 1998).

In an attempt to see if these widely dispersed experiences with pre-testing in the collegiate environment had merit for aviation students, in 2006 a study was conducted using two different sections of the Introduction to Aerospace course at Middle Tennessee State University (Beckman, 2008). In the study, one section of Introduction to Aerospace students was given a detailed set of learning objectives at the beginning of each unit of study. The other section of the course was administered a pre-test at the beginning of each unit. The results of this study indicated that there was a statistically significant difference in mean post-test scores between the class that received learning objectives and the class which experienced pretesting before each unit. The performance on each unit test was compared, and in each case the pre-test class mean score was significantly higher than the mean score of the class which was distributed learning objectives. The final exam scores for the class which was administered pre-tests were also significantly higher than the class which received learning objectives, pointing towards the possibility that the students were not only better prepared for the initial unit tests, but that the knowledge stayed with them for a longer time.

\section{STATEMENT OF THE PROBLEM}

Given the success experienced in the previous study of the Introduction to Aerospace class, it was felt worthwhile to replicate the study with a different group of students, and in a different course. As in the previous study, two sections of a particular course, this time Private Pilot Fundamentals, were utilized. One section received learning objectives for each unit, while the other section experienced a pre-test for each 
unit. The learning objectives distributed were more than a "study guide" for a particular test, as these objectives were handed out at the beginning of each unit and students were encouraged to track their progress in mastering the objectives as the class moved through the unit. The pre-tests developed for each unit acted to operationalize the learning objectives for the students. The unit post-tests for the class were developed from the learning objectives for the unit, and were not identical to the pre-tests. In Table 1, a short list of representative examples of both learning objectives and pre-test questions from each unit can be seen.

Table 1. Comparison of Learning Objectives and Pre-Test Questions

\begin{tabular}{|c|c|}
\hline $\begin{array}{c}\text { Examples of Learning Objectives from } \\
\text { Each Unit }\end{array}$ & $\begin{array}{l}\text { Examples of Pre-test Questions from Each } \\
\text { Unit }\end{array}$ \\
\hline \multicolumn{2}{|l|}{ Unit One } \\
\hline $\begin{array}{l}\text { - Be able to discuss lift from both Newton's } \\
\text { and Bernoulli's perspectives }\end{array}$ & $\begin{array}{l}\text { - Explain how Bernoulli's principle describes the lift } \\
\text { generated by an airfoil }\end{array}$ \\
\hline $\begin{array}{l}\text { - Be able to discuss fuel system components of } \\
\text { a piston-powered aircraft }\end{array}$ & - What is the purpose of an aircraft mixture control? \\
\hline \multicolumn{2}{|l|}{ Unit Two } \\
\hline $\begin{array}{l}\text { - Be able to correctly interpret the information } \\
\text { depicted on a sectional chart }\end{array}$ & $\begin{array}{l}\text { - Determine the frequency on which to contact } \\
\text { Chattanooga Approach Control if approaching from } \\
\text { the north }\end{array}$ \\
\hline $\begin{array}{l}\text { - Be able to describe the depictions of and /or } \\
\text { requirements of Class A, B, C, D, E, and G } \\
\text { airspace }\end{array}$ & $\begin{array}{l}\text { - What class airspace exists at } 3000 \text { feet MSL } \\
\text { directly over the Nashville International Airport, and } \\
\text { what are the requirements of this airspace in terms of } \\
\text { communication, equipment, and weather minimums? }\end{array}$ \\
\hline \multicolumn{2}{|l|}{ Unit Three } \\
\hline $\begin{array}{l}\text { - Be able to explain the particular hazards a } \\
\text { thunderstorm can present to an aircraft }\end{array}$ & $\begin{array}{l}\text { - Describe the hazards present for aircraft in a } \\
\text { microburst. }\end{array}$ \\
\hline $\begin{array}{l}\text { - Be able to correctly decode and interpret } \\
\text { PIREPS }\end{array}$ & $\begin{array}{l}\text { - Given a particular PIREP, at what altitude were the } \\
\text { bases and tops of the reported broken layer? }\end{array}$ \\
\hline \multicolumn{2}{|l|}{ Unit Four } \\
\hline - Be able to determine aircraft takeoff distance & $\begin{array}{l}\text { - Determine the takeoff distance over a } 50 \text { foot } \\
\text { obstacle for a DA- } 40 \text {, given a pressure altitude of } \\
2000 \text { feet, a temperature of } 12^{\circ} \mathrm{C} \text {, a weight of } 2250 \\
\text { pounds, and a } 8 \text { knot headwind. }\end{array}$ \\
\hline $\begin{array}{l}\text { - Be able to determine magnetic heading for a } \\
\text { given cross country flight }\end{array}$ & $\begin{array}{l}\text { - Given a cross country from MBT to HSV, with } \\
\text { winds at the cruising altitude reported as } 240^{\circ} \text { at } 18 \\
\text { knots, determine the magnetic heading for this flight }\end{array}$ \\
\hline
\end{tabular}

\section{RESEARCH METHODOLOGY}

During the spring 2007 semester, two sections of the Private Pilot Fundamentals course at MTSU were used to compare the effectiveness of the two methods. The first section was designated the "Pre-test class," and comprised a population of 17 students. The second section, designated the "Learning Objectives class," consisted of 21 students. There was no student attrition in the Pre-test class, while the attrition rate for the Learning Objectives class was $4.76 \%$ (one student). The test grades of the student who withdrew before the completion of the term were not used in the study. The demographics of the two classes were very similar, with the Pre-test class having a minority percentage of $12 \%$, a female percentage of $0 \%$, and $71 \%$ of the students classified as freshmen. The Learning Objectives class had a minority percentage of $4 \%$, a female percentage of $4 \%$, and $76 \%$ of the students classified as freshmen.

It was important to determine that the two classes were not significantly different in terms of academic ability before starting the study. Since pre-testing both groups at the start of the 
semester would have defeated the purpose of this study, it was not possible to utilize this typical methodology. Instead, the cumulative college GPA's of the students in each class were examined at the start of the semester, and a two sample t-test was performed to determine if there was a significant difference between these GPA's. The Pre-testing class had a mean GPA of $2.671 \quad(\sigma=.5966)$ while the Learning Objectives class had a mean GPA of 2.495 $(\sigma=.6352)$. The t-test revealed that there was not a significant difference in these GPA's, t (36) = $.8692, \mathrm{p}<0.05$, so both groups of students were equally adept academically.

The Private Pilot Fundamentals course supports the first semester of combined Private/Instrument flight training at the MTSU flight school. The first unit of the class is dedicated to basic aerodynamics and aircraft systems; the second unit to airspace, charts, the airport environment, and communications; the third unit to meteorology, interpreting pilot weather resources, and aircraft performance; and the fourth unit to cross country flight planning, Federal Aviation Regulations, and physiology. Thus, the course is divided into four separate units, and after each unit there is a post-test.

In order to compare the effectiveness of the two methods of instruction, the Learning Objectives class was given a list of specific learning objectives for each unit on the day of class we started into that particular unit. The Pre-test class was administered a pre-test on the day of class we began each unit, with each pretest question corresponding to a particular learning objective. These pre-tests were scored, recorded, and returned to the student. Besides this difference, the two sections of the class were given identical treatments, i.e., they were taught in the same manner, and by the same instructor. The results of students in both sections on the unit post-tests were subsequently recorded, for use in determining which method of instruction was more effective. The null hypothesis for the study was: There is no difference between the post-test scores of the Private Pilot Fundamentals students being given a pre-test prior to each unit of study and the class of Private Pilot Fundamentals students being given a list of unit learning objectives prior to each unit of study.

\section{DATA ANALYSIS}

The data from each of the two classes was first analyzed at a macroscopic level, using a per-student cumulative test average over all four unit tests. As can be seen by Figure 1 and Figure 2, the student test results were approximately normally distributed in each case.

A two sample t-test assuming unequal variances was used to determine the $t$ values at the .05 level of significance. This test revealed a significant difference between the overall test averages of the two classes, $t(34)=1.768$, $\mathrm{p}<0.05$. The results of this t-test may be seen in Table 2.

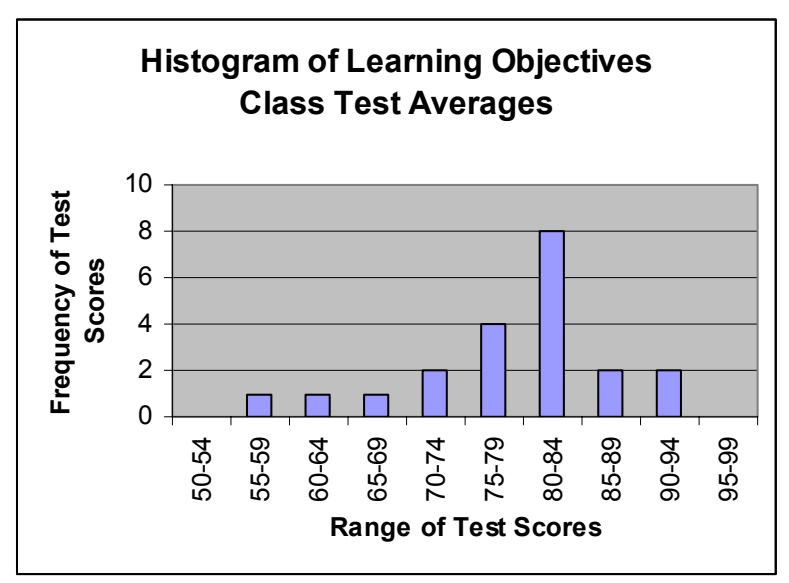

Figure 1. Learning Objectives

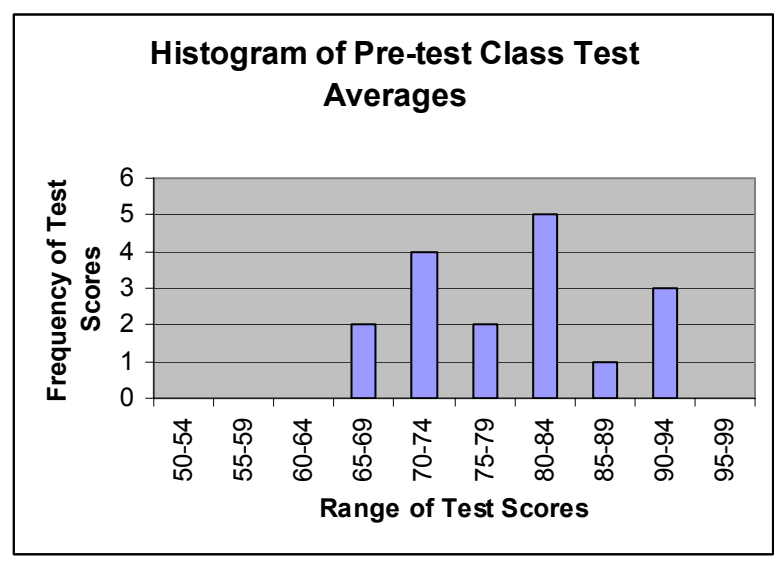

Figure 2. Pre-test Averages 
Table 2. Comparison of the Two Classes' Overall Unit Test Averages

\begin{tabular}{|l|l|l|}
\hline \multicolumn{1}{|c|}{$\begin{array}{c}\text { t-Test: Two-Sample Assuming Unequal } \\
\text { Variances }\end{array}$} & & \\
\hline & Pre-test Class & Learning Objectives Class \\
\hline Mean & 79.5735 & 74.5119 \\
\hline Variance & 78.0528 & 75.7030 \\
\hline T Stat & 1.7680 & \\
\hline T Critical two-tail & 1.6883 & \\
\hline
\end{tabular}

Next, a comparison of student performance on each of the four individual unit tests was conducted, to determine if the pre-testing procedure had an impact in each particular unit. The descriptive statistics and the results of the two sample t-tests for each unit may be seen in Tables 3-6. In Table 3, it can be seen that there was a significant difference between the test one scores of the two classes, $t(36)=1.7440, \mathrm{p}$ $<0.05$. In Table 4 and Table 5 , it can be seen that there was not a significant difference between the test two and test three scores of the two classes. In Table 6 it can be seen that there was a significant difference between the test four scores of the two classes, $t(36)=2.6345$, $\mathrm{p}<0.05$, with this being the largest difference of the four tests.

Table 3. Comparison of Test One Scores

\begin{tabular}{|l|l|l|}
\hline $\begin{array}{l}\text { t-Test: Two-Sample } \\
\text { Assuming Unequal } \\
\text { Variances }\end{array}$ & & \\
\hline & $\begin{array}{l}\text { Pre-test } \\
\text { Class }\end{array}$ & $\begin{array}{l}\text { Learning } \\
\text { Objectives Class }\end{array}$ \\
\hline Mean & 79.6471 & 73.9524 \\
\hline Variance & 96.6176 & 104.5476 \\
\hline T Stat & 1.7440 & \\
\hline T Critical two-tail & 1.6883 & \\
\hline
\end{tabular}

Table 4 Comparison of Test Two Scores

\begin{tabular}{|l|l|l|}
\hline $\begin{array}{l}\text { t-Test: Two-Sample } \\
\text { Assuming Unequal } \\
\text { Variances }\end{array}$ & & \\
\hline & $\begin{array}{l}\text { Pre-test } \\
\text { Class }\end{array}$ & $\begin{array}{l}\text { Learning } \\
\text { Objectives Class }\end{array}$ \\
\hline Mean & 79.0588 & 77.9048 \\
\hline Variance & 91.5588 & 79.9905 \\
\hline T Stat & .3806 & \\
\hline T Critical two-tail & 1.6883 & \\
\hline
\end{tabular}

Table 5. Comparison of Test Three Scores

\begin{tabular}{|l|l|l|}
\hline $\begin{array}{l}\text { t-Test: Two-Sample } \\
\text { Assuming Unequal } \\
\text { Variances }\end{array}$ & & \\
\hline & $\begin{array}{l}\text { Pre-test } \\
\text { Class }\end{array}$ & $\begin{array}{l}\text { Learning } \\
\text { Objectives Class }\end{array}$ \\
\hline Mean & 78.7647 & 76.2857 \\
\hline Variance & 148.5662 & 99.3143 \\
\hline T Stat & .6755 & \\
\hline T Critical two-tail & 1.6883 & \\
\hline
\end{tabular}

Table 6. Comparison of Test Four Scores

\begin{tabular}{|l|l|l|}
\hline $\begin{array}{l}\text { t-Test: Two-Sample } \\
\text { Assuming Unequal } \\
\text { Variances }\end{array}$ & $\begin{array}{l}\text { Pre-test } \\
\text { Class }\end{array}$ & $\begin{array}{l}\text { Learning } \\
\text { Objectives Class }\end{array}$ \\
\hline Mean & 80.8236 & 69.9048 \\
\hline Variance & 141.6544 & 185.4905 \\
\hline T Stat & 2.6354 & \\
\hline T Critical two-tail & 1.6883 & \\
\hline
\end{tabular}

It was also interesting to compare the amount of gain in scores from pre-test to posttest for the Pre-test class, which of course, was not possible for the Learning Objectives class. As can be seen in Table 7, the class had an overall pre-test mean of 48.65 , as compared to an overall post-test mean of 79.57 , representing a gain of around 31 points. If performance on each of the individual unit pre-tests and posttests are compared, an average gain of approximately 30 points is seen on the first test, with average gains of 27 points, 33 points, and 30 points seen on the second, third, and fourth tests, respectively. An analysis of pre-test versus post-test scores was evaluated for the Pretest class, to verify that there was indeed significant impact from the instruction students received. At $\mathrm{t}(27)=7.6673, \mathrm{p}<0.05$, there was a significant difference between the average pretest and post-test scores, as seen in Table 7. 
Table 7. Comparison of Pre-test Class Pre-test and Post-test Results

\begin{tabular}{|l|l|l|}
\hline $\begin{array}{l}\text { t-Test: Two-Sample Assuming Unequal } \\
\text { Variances }\end{array}$ & & \\
\hline & Average Post-test Scores & Average Pre-test Scores \\
\hline Mean & 79.5735 & 48.6471 \\
\hline Variance & 78.0528 & 198.5317 \\
\hline T Stat & 7.6673 & \\
\hline T Critical two-tail & 2.0518 & \\
\hline
\end{tabular}

While this result was obviously expected, it is mentioned here because the amount of improvement seemed to have a psychological impact on the class. This phenomenon was also experienced when the study was done with students in the Introduction to Aerospace course (Beckman, 2008). Although the students' graded pre-tests were simply returned to them with no further mention made of the event, the students were very interested in seeing "how much they had learned" in a particular unit. It seems students are motivated by the fact that they are "getting something" out of the class.

\section{DISCUSSION}

The analysis of data revealed that with regards to the cumulative average of the unit tests grades, the Pre-test class performed significantly better than the Learning Objectives class. However, there were mixed results regarding the difference between the Learning Objectives class and the Pre-test class in their performance on each specific unit test. On test one and test four, the Pre-test class did significantly better, while on test two and three the difference in performance was not significant. These mixed results are in contrast to the earlier study done with the Introduction to Aerospace course, in which there was a significant difference between the Learning Objectives class and the Pre-test class in their performance on every unit test (Beckman, 2008).

There are at least two possible reasons why the pre-test procedure did not have as much impact on the Private Pilot Fundamental class. First, a smaller percentage of the Private Pilot students $(74 \%)$ were freshmen when they took the course, compared with the Introduction to Aerospace students when they took their course (90\% freshmen). Since a greater percentage of the Private Pilot Fundamentals students had been in the collegiate environment for more than two semesters, it is likely they had become accustomed to university-level test expectations, and did not need the assistance of a pre-test to operationalize those expectations. Second, since there are test guides published for Private Pilot FAA knowledge test questions, students in both sections of the course had access to those questions for test preparation. It is important to note that the primary purpose of this course is not to teach the Private Pilot knowledge test questions, but instead to provide students the aeronautical knowledge to be safe and effective Private Pilots. As such, no class time is spent reviewing specific FAA knowledge test questions. However, $20-25 \%$ of the questions on each unit test are modeled after the FAA Private Pilot knowledge test questions relevant to the topics covered in the unit, as a method of compelling the students to begin preparing for the FAA knowledge test they will eventually need to complete. The fact that knowledge test questions are included on the unit tests is communicated clearly to the students at the beginning of the course. Thus, all students could have had exposure, prior to the post-test, of $20-25 \%$ of the test material, if they chose to study the published FAA knowledge test questions related to the topics in that unit.

\section{CONCLUSIONS}

While the results of this study were not as compelling as those found previously with the Introduction to Aerospace class, there was still a significant difference in the average unit test scores achieved by the section of Private Pilot Fundamentals that experienced pre-testing. However, while the mean of each unit test was higher for the Pre-testing class, it was only statistically significant for unit test one and unit 
test four. As mentioned in the Discussion section, this seems to indicate that pre-testing is more helpful for classes in which a large majority of students are freshmen. In addition, for classes in which some percentage of unit test questions are from a particular FAA knowledge test question bank, the advantage of pre-testing is not as great since those questions are available for student use. However, taking a pre-test involves active instead of passive learning, so for those students whose learning style leans toward active, pre-testing may still be beneficial. In addition, the psychological benefit of seeing how much is being learned can aid students in seeing the value of a course, and therefore increase motivation.

The largest problem identified with conducting a class using pre-tests is that the instructor has to be very clear regarding their objectives at the outset of each unit. Since the specific learning objectives for this course had already been developed, it was not too difficult to develop pre-test assessment items from these objectives. Had the objectives not existed, it would have been impossible to develop appropriate assessment items without first developing the learning objectives.

Another difficulty is developing numerous high-quality test questions on a specific topic. Since different questions need to be used on the pre-tests and post-tests, a large bank of questions must be developed. This is somewhat more difficult and time consuming than just creating the usual post-test assessments. An additional concern was the amount of class time it would take to conduct the pre-tests. In reality, most students did not know enough about the topics to spend much time working on the pre-tests. In addition, learning was taking place in the pretest situation; it was just a different type of learning than customarily experienced. Through the pre-tests, students were able to identify the areas of upcoming study which they had either not yet been exposed to or had not yet understood in a very hands-on manner.

One other identified disadvantage of pretesting is that there probably is not as much "peripheral" student learning as there is in classes without pre-testing. There are obviously any number of topics that do not rank as "most important" to an instructor, but that may in fact be an area of interest to a particular student. Had students not been given a pre-test (or even the list of learning objectives, for that matter) and therefore realized the instructor did not consider a particular area important, a student may have investigated a topic of interest to them in more depth. Ultimately, at this level class, it seems appropriate for students to concentrate on the areas that an instructor has determined are most important. At upper class or higher levels of coursework, this approach would not be as beneficial, as students need to learn to investigate and learn more independently.

Finally, it should be noted that the number of students in this study was obviously small, and the study should be replicated with both Private Pilot Fundamental courses and Introduction to Aerospace courses in the future to determine if the time and effort spent in developing both pre-test and post-test assessments is worth the subsequent gain in student learning. Based on the results so far, it appears that pre-testing was more helpful for students in Introduction to Aerospace classes than for Private Pilot Fundamentals students. However, pre-testing does appear to provide a slightly more effective means of communicating the objectives of a course to students than distributing learning objectives. 


\section{REFERENCES}

Angelo, T., \& Cross, K. (1993). Classroom Assessment Techniques: A Handbook for College Teachers $\left(2^{\text {nd }}\right.$ ed.). San Francisco: Jossey-Bass.

Beckman, W. (2008). Pre-testing as a Method of Conveying Learning Objectives. Journal of Aviation/Aerospace Education and Research, 17(2), 61-70.

Bernauer, J.A. (1998). Teaching for measurable outcomes. Journal on Excellence in College Teaching, $9(2), 25-46$.

Liggitt-Fox, D. (1997, February). Fighting student misconceptions: three effective strategies. Science Scope, 28-30.

Linn, R.L. \& Miller, M.D. (2005). Measurement and Assessment in Teaching ( $9^{\text {th }}$ ed.). New Jersey: Pearson.

Ochs, R.S. (1998). The first-day quiz as a teaching technique. Journal of Chemical Education, 75(4), 401-404.

Resnick, L.B., \& Resnick, D.P. (1992). Assessing the thinking curriculum: New tools for educational reform. In B.R. Gifford \& M.C. O'Connor (Eds.), Changing Assessments: Alternative Views of Aptitude, Achievement, and Instruction (pp. 37-75). Boston: Kluwer.

Shepard, L.A. (2001). The role of classroom assessment in teaching and learning. In V. Richardson (Ed.) Handbook of Research on Teaching ( $4^{\text {th }}$ ed.), (pp. 1066-1101). Washington, D.C.: American Educational Research Association.

Stiggins, R.J. (1994). Student Centered Classroom Assessment. New York: Macmillan.

Vocational Instructional Materials Lab. (1998). Applied Mathematics: Targets for Learning Strategies for Preparing Successful Problem Solvers in the Workplace (pp. 36-40). Columbus: Ohio State University. 